\title{
Rancangan Sistem Aplikasi E-learning: Studi Kasus SMK Negeri 1 Pangkalpinang
}

\author{
Ulfa Sari Febriani \\ Sistem Informasi \\ STMIK Atma Luhur \\ Jl. Jend. Sudirman Selindung Lama \\ Pangkalpinang, Babel \\ 0717-433506 \\ Usari.febriani@gmail.com
}

\author{
Hamidah \\ STMIK Atma Luhur \\ Jl. Jend. Sudirman, Selindung, \\ Pangkalbalam \\ Pangkalpinang, Bangka Belitung \\ 0717-433506 \\ hamidah@atmaluhur.ac.id
}

\author{
Okkita Rizan \\ STMIK Atma Luhur \\ J1. Jend. Sudirman, Selindung, \\ Pangkalbalam \\ Pangkalpinang, Bangka Belitung \\ 0717-433506 \\ orizan@atmaluhur.ac.id
}

\begin{abstract}
Teaching and learning process in SMK Negeri 1 Pangkalpinang are still conventional, where the students and teacher activities are only conducted in classroom. Various teaching concepts and techniques have been developed to complement the conventional methods that rely solely on a oneway method of learning andteaching in the classroom. One of teaching methods is currently being developed is e-learning. $\mathrm{E}$ learning is Teachers'aid in distributing their materials where they must not attend in classroom, but use internet access. It is the best way to maximized the studying time in limited rooms.Elearning could help teaching and learning process more efficient. To realize E-learning Application in SMK Negeri 1 Pangkalpinang, it can be carried out by Learning Management System (LMS) design using Moodle. Moodle (Modular Object Oriented Dynamic Learning Environment) is one off the free LMS that can be downloaded, be utilized and be modified with a license as GPU (General Public License). The E-learning website will be used as additional discussion media for discussing unfinished learning materials, and multiple-choice exams and submitted tasks.
\end{abstract}

Keywords - component; formatting; style; styling; insert (key words)

\section{Pendahuluan}

Lembaga pendidikan adalah salah satu tolak ukur kemajuan suatu bangsa. Apalagi di era globalisasi seperti ini, dunia pendidikan dituntut agar selalu meningkatkan kualitasnya agar Indonesia dapat bertahan dan mampu menyesuaikan diri di era keterbukaan informasi ini. Sekolah sebagai salah satu lembaga pendidikan juga dituntut untuk mampu memberikan pelayanan publik, baik sekolah negeri maupun swasta. Karena adanya beberapa kesulitan yang dialami siswa dalam proses pembelajaran konvensional di kelas seperti kurangnya waktu untuk berdiskusi dengan guru, proses belajar dikelas yang monoton, kurang beragamnya contoh kasus dan soal latihan di kelas dan lain sebagainya.Untuk itu demi terciptanya konsep dan mekanisme proses pembelajaran yang lebih baik, tidak terkonsentrasi oleh tempat dan waktu dan mendukung sistem pembelajaran konvensional, pelayanan yang sedang penulis rancang adalah aplikasi elearning dengan menggunakan moodle bagi kalangan siswa dan guru yang bisa diakses melalui jaringan internet.Elearning sendiri merupakan konsep pembelajaran secara elektronik ataupun Distance Learning (Pembelajaran Jarak Jauh). Dengan konsep ini sistem belajar mengajarakan tidak terbatas ruang dan waktu. Moodle merupakan sistem aplikasi yang berbasis web yang berguna sebagai media untuk proses pembelajaran jarak jauh atau e-learning. Aplikasi ini memungkinkan siswa untuk masuk ke dalam "ruang kelas" digital untuk mengakses materi - materi pembelajaran. Dengan menggunakan moodle, kita dapat membuat materi pembelajaran, kuis, jurnal elektronik dan lain - lain. Moodle itu sendiri adalah singkatan dari Modular Object Oriented Dynamic Learning Environment. Moodle adalah salah satu Learning Management System (LMS), yang gratis dapat di download, digunakan ataupun dimodifikasi oleh siapa saja dengan lisensi secara GPU (General Public License). Saat ini sudah terdapat lebih dari 49.000 situse-Learning tersebar di lebih dari 210 negara yang dikembangkan dengan Moodle. Selain itu Moodle mempunyai 45 paket bahasa, termasuk bahasa Indonesia. Hal ini tentu memudahkan dalam proses pengeditan karena dapat menggunakan editor yang telah tersedia.

\section{TINJAUAN PUSTAKA}

\section{A. E-Learning (Electronic Learning)}

E-learning adalah kegiatan pelatihanyang menggunakan media elektronik atau teknologi informasi [1]. Berbagai istilah yang digunakan untuk mengartikan e-learning antara lain, web-based learning, online learning, computerbased training/learning, distance learning, computer-aided instruction, dan lain-lain.

E-learning merujuk pada pembelajaran yang didukung melalui web yang dapat digunakan dalam kelas biasa atau kelas virtual [2]. E-learning adalah suatu bentuk pendidikan yang menggabungkan motivasi diri sendiri, komunikasi, efisiensi, dan teknologi. Dikarenakan adanya keterbatasan interaksi sosial, pelajar harus menjaga agar 
mereka tetap termotivasi. E-learning cukup efisien dengan menghilangkan jarak dan kendala lain, dimana jarak dihilangkan karena e-learning dibuat dengan media yang dapat diakses dengan perangkat yang berhubungan dengan internet.

\section{B. Tipe-tipe E-Learning}

Pada dasarnya e-learning mempunyai dua tipe [2] yaitu:

\section{1) Synchronous Training}

Synchronous berarti "pada waktu yang sama". Synchronous training adalah tipe pelatihan, dimana proses pembelajaran terjadi pada saat yang sama ketika pengajar sedang mengajar dan murid sedang belajar. Hal tersebut memungkinkannya interaksi langsung antara guru dan murid, baik melalui intranet maupun internet. Synchronous training mengharuskan guru dan murid mengakses internet bersamaan

\section{2) Asynchronous Training}

Asynchronous berarti "tidak pada waktu yang bersamaan". Jadi, seseorang dapat mengambil pelatihan pada waktu yang berbeda dengan pengajar memberikan pelatihan. Pelatihan ini lebih populer di dunia e-learning karena memberikan keuntungan lebih bagi peserta pelatihan karena dapat mengakses pelatihan kapanpun dan dimanapun.

\section{Fungsi E-Learning}

Setidaknya ada 3 (tiga) fungsi pembelajaran elektronik terhadap kegiatan pembelajaran di dalam kelas (classroom instruction) [1][5] yaitu:

\section{1) Suplemen (Tambahan)}

Dikatakan berfungsi sebagai suplemen, apabila peserta didikmempunyai kebebasan memilih, apakah akan memanfaatkan materipembelajaran elektronik atau tidak. Dalam hal ini, tidak ada kewajiban/keharusan pembelajaran elektronik. Sekalipun sifatnya opsional, peserta didik yang memanfaatkannya tentu akan memiliki tambahan pengetahuan atau wawasan.

\section{2) Komplemen (Pelengkap)}

Dikatakan berfungsi sebagai komplemen, apabila materi elearning diprogramkan untuk melengkapi materi pembelajaran yang diterirna siswa di dalam kelas (Lewis, 2002). Sebagai komplemen berarti materi e-learning diprogramkan untuk menjadi materi enrichment (pengayaan) atau remedial bagi peserta didik di dalam mengikutikegiatan pembelajaran konvensional. Sebagai enrichment, apabila peserta didik dapat dengan cepat menguasai/memahami materi pelajarsn yang disampaikan guru secara tatap muka diberikan kesempatan untuk mengakses materi elearning yang memang secara khusus dikembangkan untuk mereka. Tujuannya agar semakin memantapkan tingkat penguasaan peserta didik terhadap materi pelajaran yang disajikan guru di kelas. Sebagai remedial, apabila peserta didik mengalami kesulitan dalam memahami materi petajaran yang disampaikan guru secara tatap muka di kelas. Tujuannya agar peserta didik semakin lebih mudah memahami materi pelajaran yang disajikan guru di kelas.

\section{3) Substitusi (Pengganti)}

Tujuan dari e-learning sebagai pengganti kelas konvensional adalah agar peserta didik dapat secara fleksibel mengelola kegiatan pembelajaran sesuai dengan waktu dan aktivitas lain sehari-hari. Ada 3 (tiga) alternatif model kegiatan pembelajaran yang dapat diikuti peserta didik:

- Sepenuhnya secara tatap muka (konvensional)

- Sebagian secara tatap muka dan sebagian lagi melalui internet, atau bahkan Sepenuhnya melalui internet.

\section{Moodle}

Moodle Modular Object Oriented Dynamic Learning Environment) merupakan salah satu LMS open source yang dapatdiperoleh secara bebas melalui http://moodle.org. Moodle adalah sebuah perangkat lunak yang berguna untuk membuat dan mengadakan kursus/pelatihan/pendidikan berbasis internet [3][6]. Moodle termasuk dalam model CAL+CAT (Computer Assisted Learning + Computer Assisted Teaching) yang disebut LMS (Learning Management System). Learning Management System (LMS) adalah perangkat lunak yang digunakan untuk menyampaikan materi pembelajaran dan resources multimedia secara online berbasis web, mengelola kegiatan pembelajaran serta hasil-hasilnya, memfasilitasi interaksi, komunikasi, kerjasama antar pengajar dan peserta didik.

\section{E. UML (Unified Modeling Language)}

UML(Unified Modeling Language) adalah sekumpulan pemodelan konvensi yang digunakan untuk menentukan atau menggambarkan sebuah sistem perangkat lunak dalam kaitannya dengan objek [4].Notasi yang lengkap untuk membuat visualisasi model suatu sistem. Sistem berisi informasi dan fungsi, tetapi secara normal digunakan untuk memodelkan sistem komputer. Di dalam pemodelan obyek guna menyajikan sistem yang berorientasi pada objek pada orang lain, akan sangat sulit dilakukan jika pemodelan tersebut dilakukan dalam bentuk kode bahasa pemrograman. Kesulitan yang muncul adalah timbulnya ketidakjelasan dan salah interpretasi di dalam pembacaan kode pemrograman untuk pemodelan objek tersebut. Dimulai tahun 1994, Booch, Runbaugh dan Jacobson merupakan tiga tokoh yang metodelogi-nya paling banyak dipakai mempelopori organisasi yang bertujuan menyatukan metodelogi-metodelogi berorientasi objek, organisasi tersebut dinamakan OMG (Object Modelling Group). Pada tahun 1995 OMG merealisasi draf pertama dari UML (versi0.8) dan pada tahun 1997 UML versi 1.1 muncul dan sekarang versi terbaru dari UML adalah versi 2.0. Pada tahun 1997 Booch, Runbaugh dan Jacobson menyusun tiga buku tentang UML. Sejak saat itulah UML telah menjelma menjadi standar bahasa pemodelan untuk aplikasi berorientasi objek. 


\section{METODE PENELITIAN}

Metodologi yang digunakan dalam penelitian:

\section{A. Pengumpulan Data}

Pengumpulan data yang dilakukan untuk mencari metode yang tepat dan efisien dalam mencari referensi e-learning, dengan metode observasi dimana dilakukan pengamatan lapangan secara langsung tentang sistem pendidikan yang sedang berlangsung di SMK Negeri 1 Pangkalpinang dan studi kepustakaan, yaitu membaca buku-buku yang berkaitan dengan masalah ini, dan dengan menggunakan informasi dari internet untuk belajar dari pengalaman orang yang telah terdokumentasi.

\section{B. Analisa dan Perancangan}

Analisa dan pengamatan lapangan yang kemudian dilanjutkan dengan perancangan.

\section{Pengimplementasian}

Implementasi hasil rancangan hingga percobaan semua data masuk ke dalam database dan ditampilkan dalam website moodle.

\section{HASIL DAN PEMBAHASAN}

Hasil dan pembahasan disini meliputi tinjauan organisasi, analisa sistem, pemodelan sistem, rancangan basis data dan rancangan layar.

\section{A. Tinjauan Organisasi}

\section{1) Sejarah Organisasi}

SMK Negeri 1 Pangkalpinang merupakan sekolah kejuruan bidang Bisnis Manajemen dan Teknik Informatika yang memiliki bangunan 2.816,5 meter persegi, berada pada lokasi seluas 9.495 meter persegi beralamat di Jalan Merdeka No 90 Kelurahan Batin Tikal Kecamatan Tamansari Kota Pangkalpinang Propinsi Kepulauan Bangka Belitung. Sekolah dengan NPSN 10901156 ini didirikan pada tanggal 01 Januari 1967 dengan SK pendirian Nomor: 73/B3/Kep/1967.Pada saat ini SMK Negeri 1 Pangkalpinang memiliki guru tetapsebanyak 58 orang dan guru tidak tetap sebanyak 5 orang.

\section{2) Struktur Organisasi}

Struktur organisasi di SMK Negeri 1 Pangkalpinang adalah sebagai berikut:

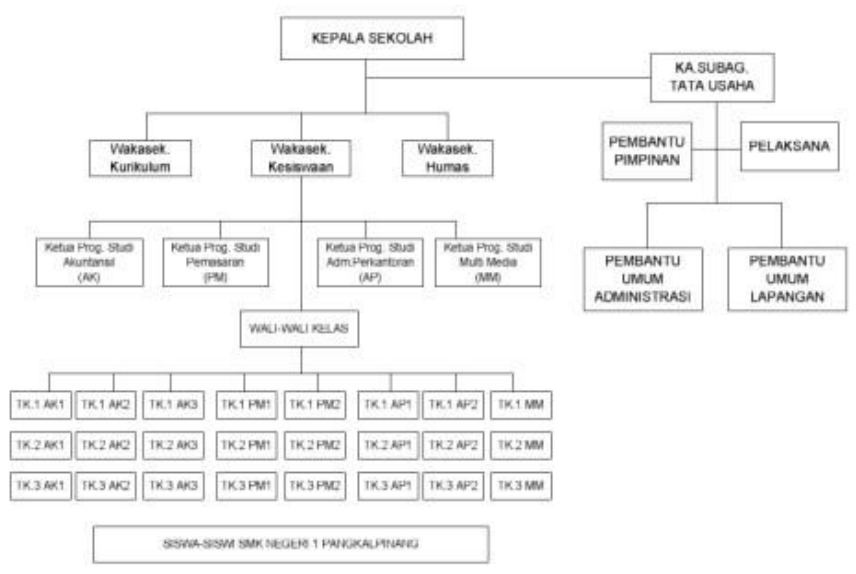

Gambar 1. Struktur Organisasi SMK Negeri 1 Pangkalpinang

\section{B. Proses Bisnis}

Proses bisnis ini adalah urutan kegiatan yang ada dalam sistem berjalan. Adapun kegiatan-kegiatannya adalah sebagai berikut :

1) Proses Penentuan Jadwal Kegiatan Belajar Mengajar Wakasek Kurikulum akan menyusun pemberian tugas guru dalam proses belajar pada tiap semester. Kemudian menyusun jadwal KBM beserta daftar nama \& kode guru pengampu mata pelajaran, yang akan menentukan jam, hari, kelas dimana guru akan memberikan pembelajaran. Guru akan datang mengajar di kelas sesuai jadwal KBM.

\section{2) Proses Kegiatan Belajar Mengajar}

Dalam pelaksanaan aktifitas pembelajaran di kelas, siswa harus hadir tepat waktu dan Guru mengabsen kehadiran para siswa. Kegiatan di dalam kelas dapat berupa penjelasan materi dan pembahasan soal - soal latihan oleh guru. Siswa mengerjakan tugas dan soalsoal latihan di kelas, kemudian mengumpulkannya. Guru menerima dan mengoreksinya, serta akan mencatat materi dan latihan yang telah diajarkan ke dalam buku agenda harian guru.

\section{3) Proses Penilaian Tugas}

Siswa hadir mengikuti pembelajaran dikelas. Guru memberikan tugas yang harus dikerjakan dirumah. Siswa mengerjakan tugas dirumah dan mengumpulkannya kembali kepada guru disekolah. Guru menerima dan mengoreksinya. Guru mencatat nilai tugas siswake dalam daftar nilai sub-sumatif. Hasil tugas yang telah dikoreksi diserahkan kembali kepada siswa.

\section{4) Proses Penilaian MID Semester}

Siswa hadir mengerjakan soal MID semester dikelas. Mengumpulkan soal \& hasil jawaban MID semester ke Guru. Guru menerima \& mengoreksi hasil jawaban MID semester siswa, serta mencatat nilai MID siswa ke dalam daftar nilai raport siswa. 
5) Proses Penilaian UUS (Ulangan Umum Semester)

Siswa hadir mengerjakan soal UUS dikelas. Mengumpulkan soal \& hasil jawaban UUS ke Guru. Guru menerima \& mengoreksi hasil jawaban UUS siswa, serta mencatat nilai UUS siswa ke dalam daftar nilai raport siswa.

\section{6) Proses Pendataan Nilai}

Guru merekap \& menghitung hasil nilai tugas dari daftar nilai sub sumatif, nilai MID \& UUS ke dalam daftar nilai raport. Guru lalu menyerahkan daftar nilai raport siswa yang telah diisi kepada Wali Kelas. Wali Kelas menerima \& menyerahkan tembusan daftar nilai raport siswa kepada Wakasek Kurikulum.

\section{7) Proses Pengisian Nilai Raport}

Wali Kelas mengisi buku raport siswa \& Ledger berdasarkan daftar nilai raport. Ledger kemudian diserahkan ke bagian TU (Tata Usaha). Bagian TU kemudian akan mencatat Ledger ke dalam buku induk siswa sebagai arsip nilai raport siswa bagi sekolah.

\section{Use Case Diagram}

menganalisis kebutuhan user dan menggambarkan interaksi pengguna dengan sistem. Dalam use case ini ada 3 aktor yang terlibat.

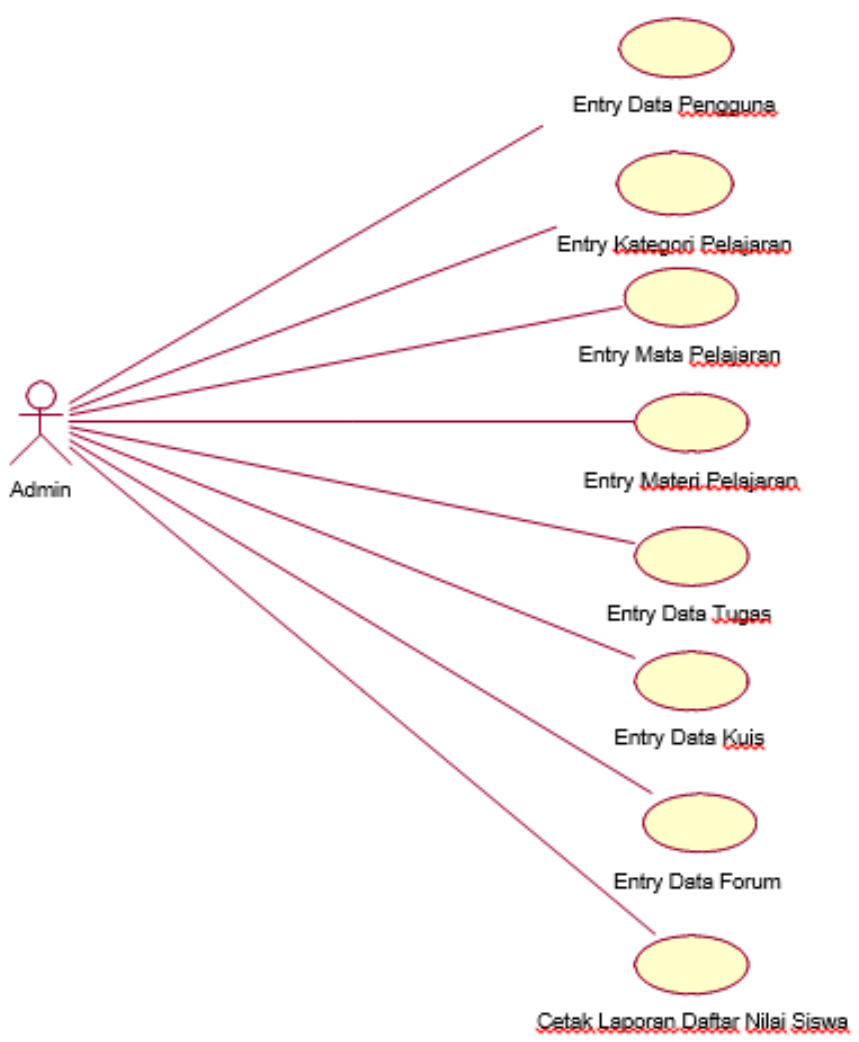

Gambar 2. Use Case Diagram Admin

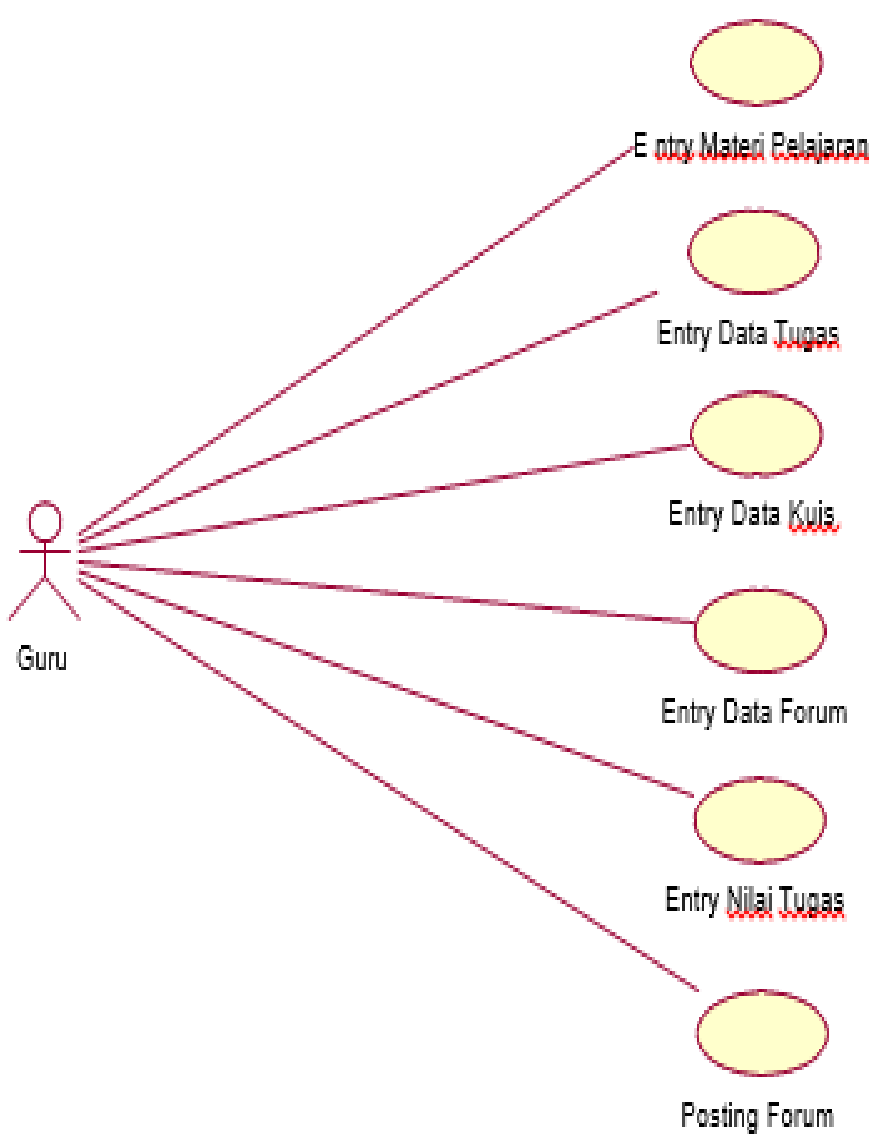

Gambar 3. Use Case Diagram Guru

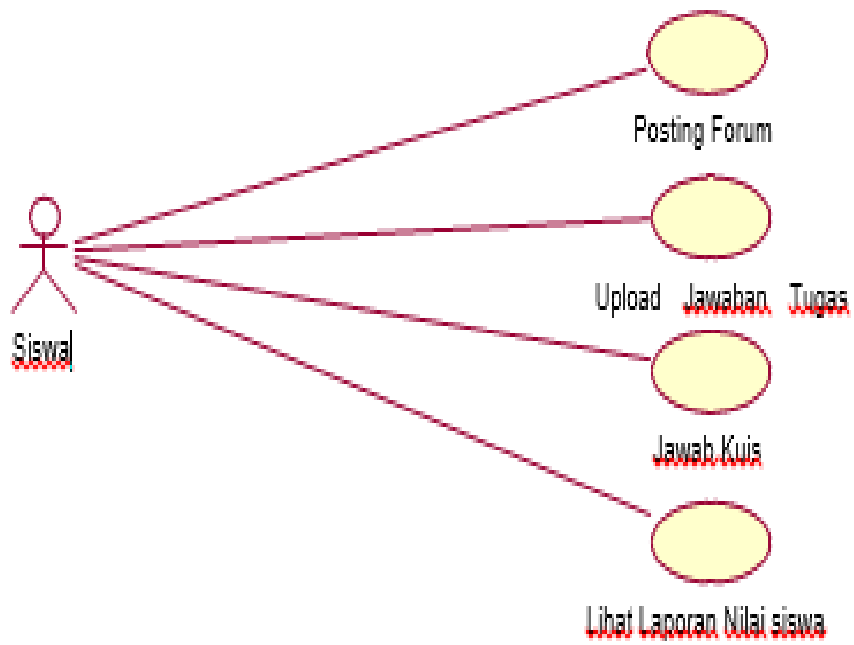

Gambar 4. Use Case Diagram Siswa

\section{Rancangan Basis Data}

Rancangan basis data digambarkan dalam Logical Record Structur (LRS) berikut : 


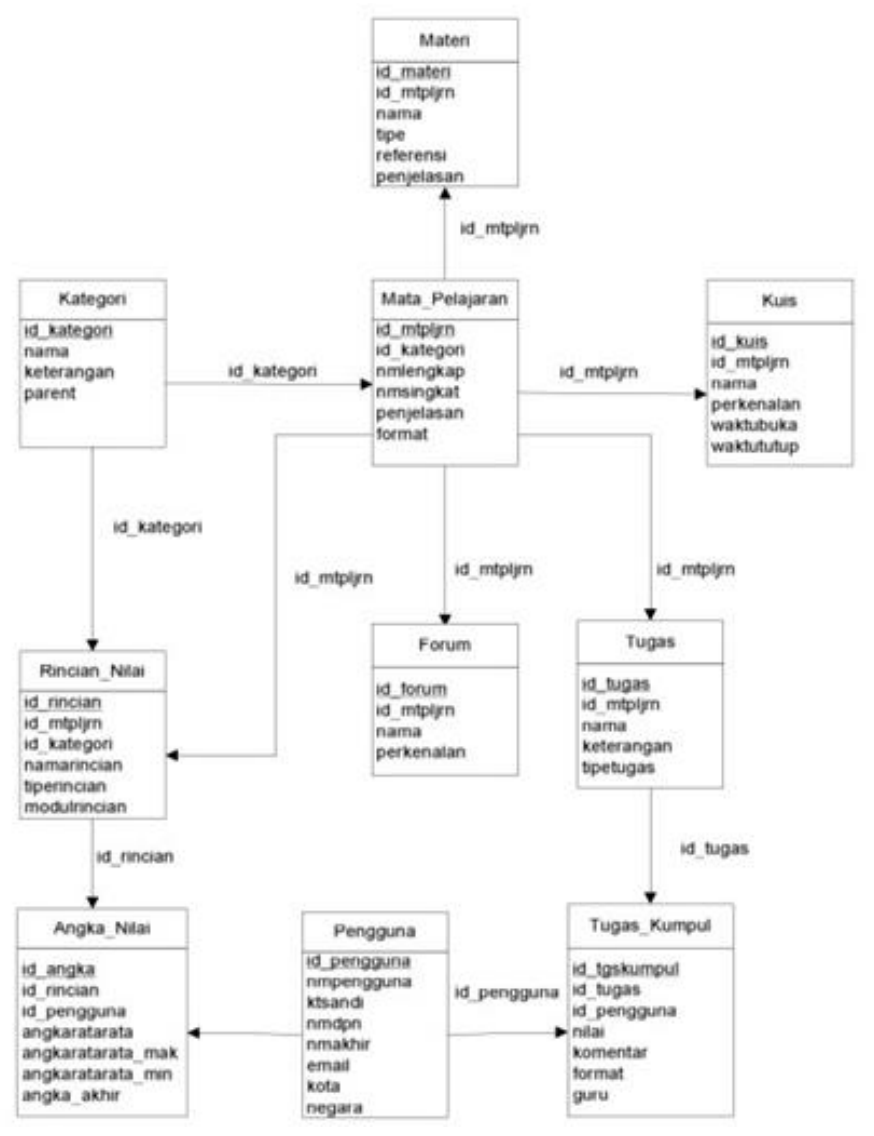

Gambar 5. LRS

Berikut table-tabel database yang diperlukan dalam penyelesaian system aplikasi e-learning ini:

1) Tabel Kategori

Tabel kategori digunakan untuk menampung data-data lengkap yang berhubungan dengan kategori pelajaran.

2) Tabel Pengguna

Tabel pengguna digunakan untuk menampung data-data lengkap yang berhubungan dengan data-data pengguna yaitu admin, guru dan siswa.

\section{3) Tabel Mata Pelajaran}

Tabel mata pelajaran digunakan untuk menampung data-data lengkap yang berhubungan dengan datadata mata pelajaran.

\section{4) Tabel Materi Pelajaran}

Tabel materi pelajaran digunakan untuk menampung data-data lengkap yang berhubungan dengan data-data materi pelajaran.

\section{5) Tabel Kuis}

Tabel kuis digunakan untuk menampung data-data lengkap yang berhubungan dengan data-data kuis pelajaran.

\section{6) Tabel Tugas}

Tabel tugas digunakan untuk menampung datadata lengkap yang berhubungan dengan data-data tugas pelajaran.

\section{7) Tabel Tugas Kumpul}

Tabel tugas kumpul digunakan untuk menampung tugas-tugas yang dikirim/dikumpul siswa.

\section{8) Tabel Forum}

Tabel forum digunakan untuk menampung data-data lengkap yang berhubungan dengan data-data forum.

\section{9) Tabel Rincian Nilai}

Tabel rincian nilai digunakan untuk menampung data-data lengkap yang berhubungan dengan data-data rincian nilai.

10) Tabel Angka Nilai

Tabel angka nilai digunakan untuk menampung nilainilai tugas dan kuis siswa.

\section{E. Rancangan Layar}

Untuk dapat mengakses website aplikasi e-learning, pengguna terlebih dahulu harus melakukan login.

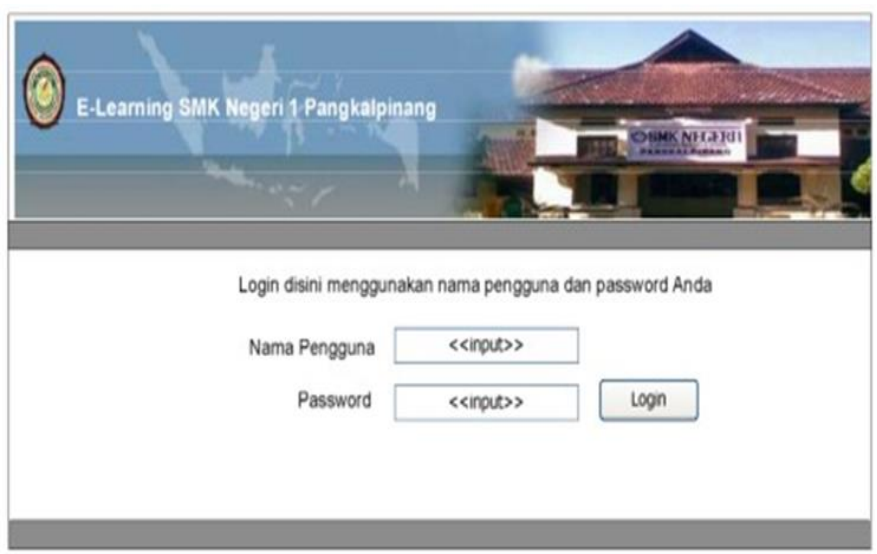

Gambar 6. Halaman Login

Setelah melakukan login bagian admin dapat menambah pengguna baru.

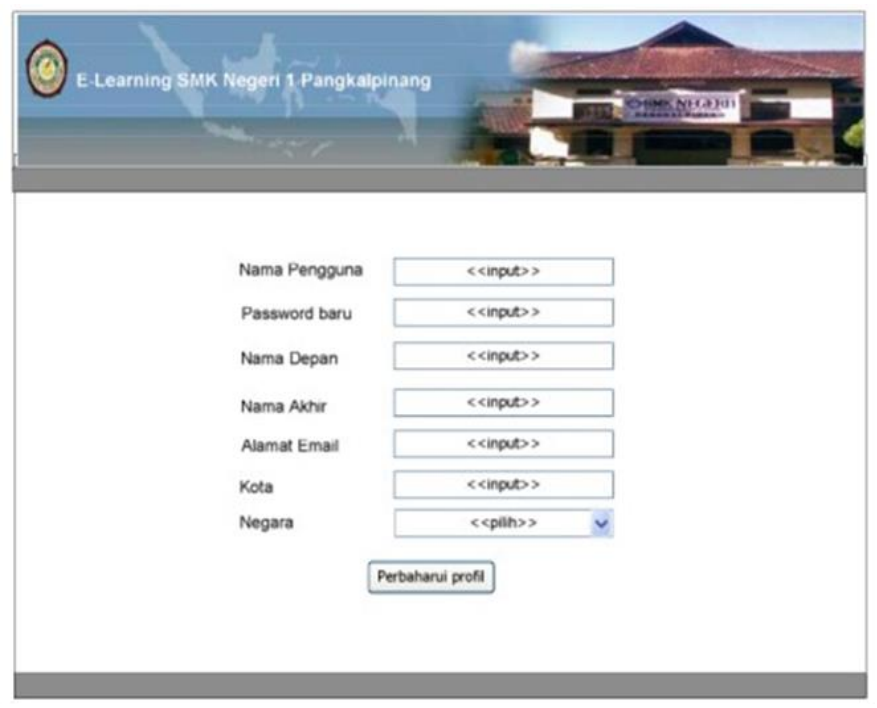

Gambar 7. Entry Pengguna 
Dan setelah admin membuat kategori dan mata pelajarannya, guru dapat menambahkan soal tugas di dalam mata pelajaran tersebut seperti dibawah ini :

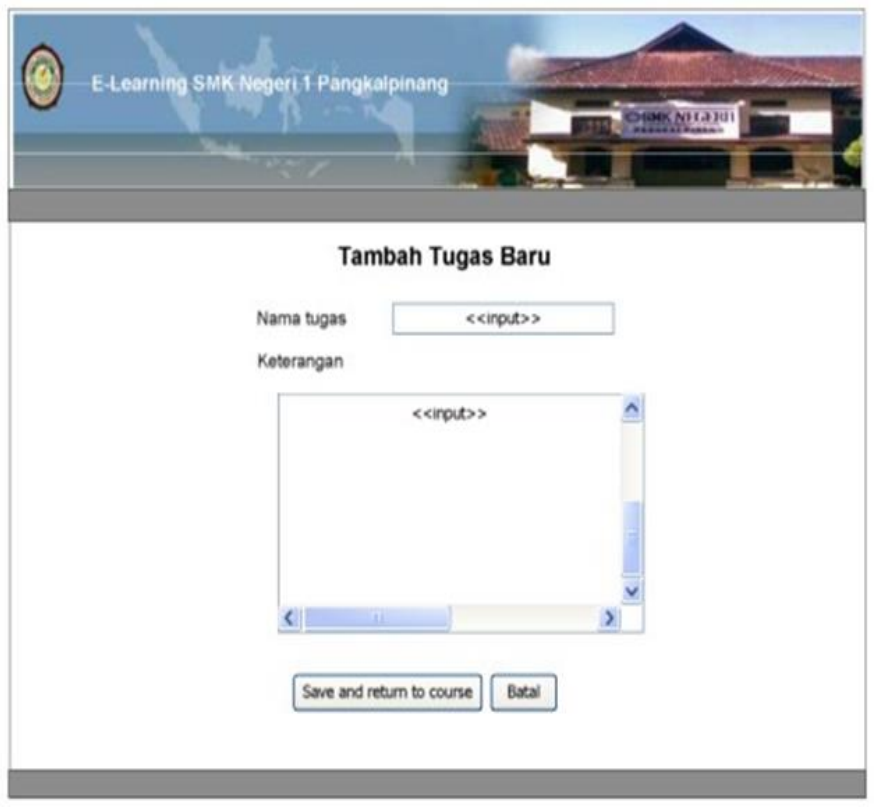

Gambar 8. Entry Tugas

Siswa yang telah login dapat mengumpulkan tugas dan melihat hasil laporan nilainya.

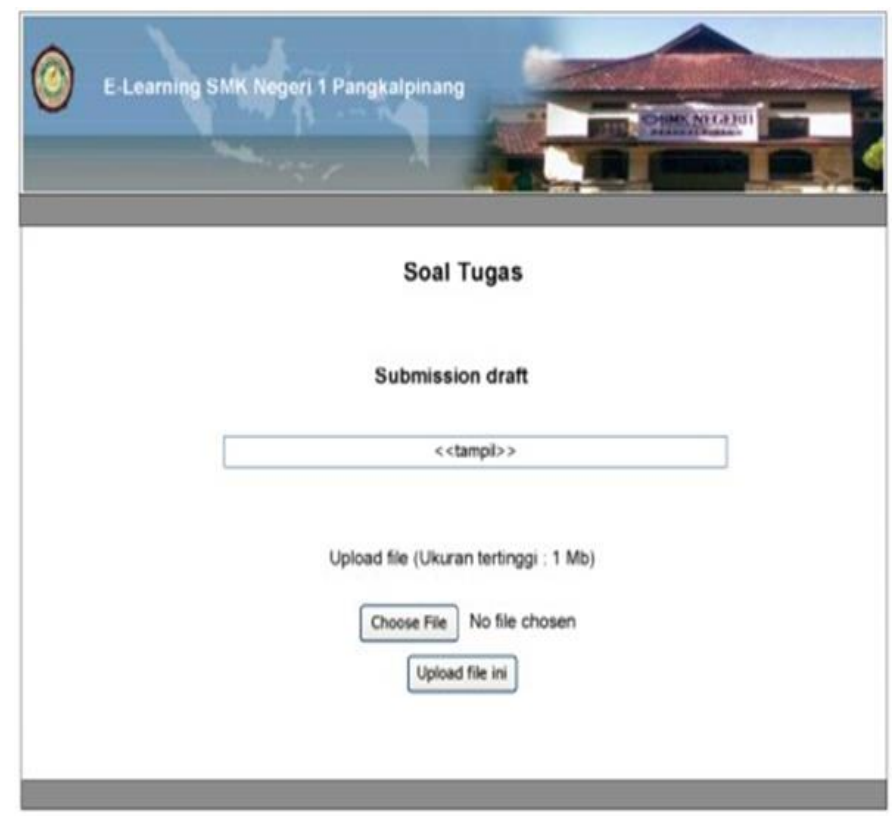

Gambar 9. Upload Jawaban Tugas

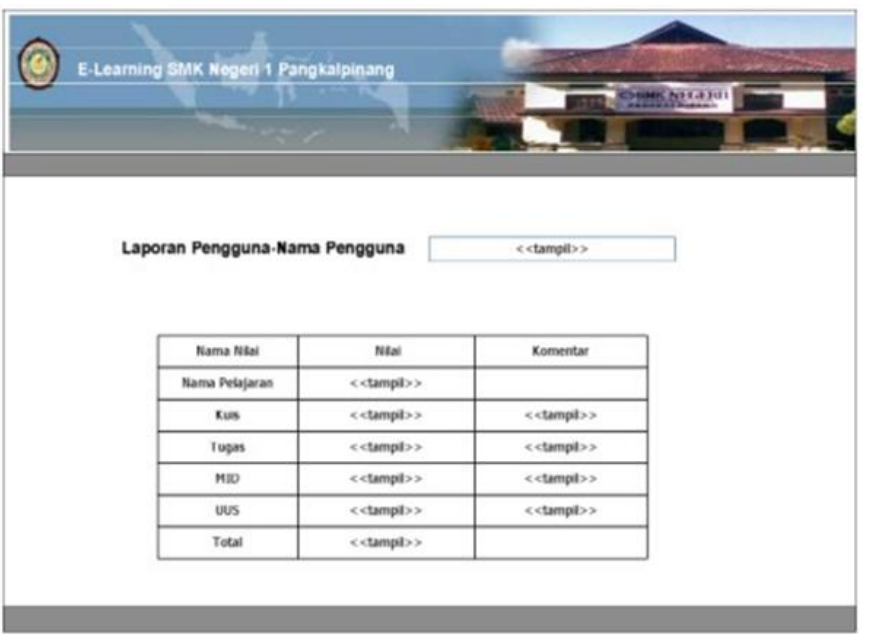

Gambar 10. Lihat Laporan Nilai Siswa

\section{PENUTUP}

\section{A. Kesimpulan}

Dari hasil analisa yang telah dijelaskan dalam laporan ini maka dapat disimpulkan berbagai hal sebagai berikut :

- Waktu yang kurang membuat materi pelajaran yang disampaikan oleh guru tidak mencapai target dan membuat siswa kurang memahami pelajaran yang telah disampaikan. Berdasarkan hal tersebut disediakan fasilitas bagi guru untuk memasukan materi-materi tambahan dan juga soal-soal tugas, sehingga siswa dapat lebih mudah mengerti mengenai pelajaran yang disampaikan.

- Fitur-fitur utama seperti pemberian materi, pemberian kuis dan tugas, serta forum diskusi sangat bermanfaat bagi pengguna dan menunjang proses pembelajaran.

- Dengan adanya aplikasi e-learning diharapkan proses belajar mengajar dapat berlangsung tidak hanya didalam kelas sehingga kualitas siswa dan guru serta proses belajar mengajar menjadi lebih baik. Dimana aplikasi ini hanya sebagai fasilitas pendukung sistem pembelajaran di SMK Negeri 1 Pangkalpinang tidak menggantikan proses belajar yang selama ini ada didalam kelas

\section{B. Saran}

Sebagai bahan pertimbangan untuk pengembangan lebih lanjut, maka disarankan untuk :

- Penambahan fitur survey untuk menilai tingkat keberhasilan dan keefektifan system e-learning ini untuk perbaikan kedepannya.

- Dari hasil penelitian, dapat diketahui bahwa program moodle ternyata memiliki banyak keuntungan apabila diaplikasikan secara nyata, namun untuk membangun program tersebut dibutuhkan beberapa hal yang menunjang agar program tersebut dapat berfungsi secara maksimal, diantaranya adalah : 
1) Tenaga ahli yang menguasai bidang komputer untuk mengelola sistem e-learning yang telah diimplementasikan.

2) Diperlukan koneksi internet yang dapat berjalan secara 24 jam non-stop.

3) Diperlukan tenaga listrik yang terus menyala.

4) Diperlukan sebuah server yang dapat menyimpan data yang cukup besar, mengingat jumlah siswa dan bahan materi akan terus bertambah.

\section{DAFTAR PUSTAKA}

[1] Bhakti, Mohammad Herdian. Implementasi Aplikasi ELearning Dengan Menggunakan Moodle. Program Studi Sistem Informasi Universitas Widyatama: Tugas Akhir Tidak Diterbitkan, 2010.

[2] Gunadarma. Pengertian E-Learning.[Online] Tersedia : http://elearning.gunadarma.ac.id, 2010 [15 Oktober 2012]

[3] Amiroh. Membangun E-Learning Moodle. [Online] Tersedia http://amiroh.web.id, 2011 [23 Juni 2013].

[4] Suhermanto, Agus. Rancangan Sistem Informasi Penjualan Online PadaLittle Brother Distro Dengan Metodologi Berorientasi Objek. Program Studi Komputerisasi Akuntansi STMIK Atma Luhur Pangkalpinang : Tugas Akhir Tidak Diterbitkan, 2010.

[5] Surjono, Herman Dwi. Membangun Course E-Learning Berbasis Moodle. Yogyakarta : UNY Press, 2010.

[6] Amiroh. Instalasi Moodle 1.9.x di Windows [Online] Tersedia http://amiroh.web.id, 2011 [23 Juni 2013] 